\title{
Use of concomitant inhaled corticosteroids: pooled data from two phase III studies of aclidinium plus formoterol in COPD
}

\author{
Anthony $\mathrm{D}^{\prime} \mathrm{Urzo}^{1}$, Dave Singh ${ }^{2}$ and Esther Garcia Gil ${ }^{3}$
}

Bronchodilator therapy is the backbone of the management of chronic obstructive pulmonary disease. In some patients, inhaled corticosteroids can be prescribed in combination with bronchodilators. Through a subgroup analysis of pooled data from two large phase III clinical trials of bronchodilator therapy according to concomitant inhaled corticosteroid use (user vs. non-user), we sought to evaluate the clinical benefit of adding inhaled corticosteroids to dual bronchodilator therapy in chronic obstructive pulmonary disease. The primary focus of this analysis of pooled data from the phase III ACLIFORM and AUGMENT studies was to evaluate the efficacy of aclidinium/formoterol on lung function stratified by inhaled corticosteroid use. We found that lung-function end points were significantly improved regardless of concomitant inhaled corticosteroid use among patients treated with the dual bronchodilator aclidinium/formoterol $400 / 12 \mu \mathrm{g}$ twice daily compared with placebo and both monotherapies. Together with the previously reported observations that aclidinium/formoterol $400 / 12 \mu \mathrm{g}$ reduces exacerbations vs. placebo in inhaled corticosteroid users and improves dyspnoea compared to monotherapy in inhaled corticosteroid non-users, these data suggest that both groups achieve lung function improvements, which translates to different clinical benefits depending on whether or not a patient is receiving concomitant inhaled corticosteroids.

npj Primary Care Respiratory Medicine (2017)27:13; doi:10.1038/s41533-016-0009-3

\section{INTRODUCTION}

The combination of aclidinium bromide $(400 \mu \mathrm{g})$, a long-acting muscarinic antagonist (LAMA), with the long-acting beta- 2 agonist (LABA) formoterol fumarate $(12 \mu \mathrm{g})$ administered twice daily is currently approved for the treatment of chronic obstructive pulmonary disease (COPD) in the European Union and in other parts of the world, including Australia and Canada. ${ }^{1-3}$ Two large phase III, randomised, double-blind, 24-week trials-ACLIFORM (NCT01462942) and AUGMENT (NCT01437397) - in patients with COPD showed significant improvements in lung function with this dual bronchodilator combination compared with placebo and monotherapies. ${ }^{4,5}$ A pooled, secondary analysis of these studies also demonstrated a significant improvement in symptoms with this dual bronchodilator combination compared to placebo and monotherapies. $^{6}$

Concomitant use of inhaled corticosteroids (ICSs) was permitted in ACLIFORM and AUGMENT, as it was considered safer to allow patients to continue on this treatment. This was particularly important for the placebo arm who received no long-acting bronchodilator maintenance therapy. The continuation of previous ICS use is a common feature of clinical studies of LABA +LAMA combination therapies ${ }^{7-9}$ and, in line with current guidelines, patients with COPD with an elevated risk for exacerbation can be prescribed ICS in combination with bronchodilators. ${ }^{10}$ However, in clinical practice many patients will use dual bronchodilator combinations without an ICS, including as a step up from long-acting bronchodilator monotherapy. Consequently, clinical trials such as ACLIFORM and AUGMENT are composed of two subgroups according to ICS use, of which ICS non-users could be considered to be the more relevant target population for dual bronchodilator combinations.

In ACLIFORM and AUGMENT, patients were not randomised to receive ICS and the studies were not designed to assess ICS use. However, the presence of an ICS-user population means that some patients were treated with 'triple therapy' (ICS+LAMA+LABA) and could be compared to patients receiving 'dual therapy' containing an ICS (ICS+LABA or ICS+LAMA).

The recently published pooled, secondary analysis of ACLIFORM and AUGMENT, stratified by concomitant ICS use, reported that, compared with placebo, aclidinium/formoterol $400 / 12 \mu \mathrm{g}$ improved dyspnoea regardless of concomitant ICS use. ${ }^{6}$ The same analysis demonstrated that the rate of exacerbations was much higher among ICS users than ICS non-users, and that aclidinium/ formoterol $400 / 12 \mu \mathrm{g}$ reduced the rate of exacerbations compared with placebo in those patients using concomitant ICS. ${ }^{6}$

The efficacy of aclidinium/formoterol on lung function, stratified by ICS use, has not yet been reported for ACLIFORM and AUGMENT and is the primary focus of this pooled, secondary analysis, since providing optimal bronchodilation is pivotal in the management of COPD. Here, we report results for the co-primary efficacy end points, change from baseline in morning pre-dose (trough) and morning 1-h post-dose forced expiratory volume in $1 \mathrm{~s}\left(\mathrm{FEV}_{1}\right)$ at Week 24

\section{RESULTS}

Of 3394 patients analysed (Table 1), 1180 (34.8\%) were ICS users and $2214(65.2 \%)$ were non-ICS users. The proportion of patients with severe COPD was greater in ICS users vs. non-ICS users at

\footnotetext{
${ }^{1}$ Department of Family and Community Medicine, Faculty of Medicine, University of Toronto, Toronto, Canada; ${ }^{2}$ The University of Manchester, Medicines Evaluation Unit, University Hospital of South Manchester Foundation Trust, Centre for Respiratory and Allergy Medicine, Manchester, UK and ${ }^{3}$ R\&D Centre, AstraZeneca, Barcelona, Spain Correspondence: Anthony D'Urzo (tonydurzo@sympatico.ca)
}

Received: 26 February 2016 Revised: 28 November 2016 Accepted: 2 December 2016 Published online: 24 February 2017 
Table 1. Patient demographics in patients with COPD using ICS and those not using ICS

\begin{tabular}{|c|c|c|}
\hline Characteristic & $\begin{array}{l}\text { Concomitant ICS } \\
\text { use }^{\mathrm{a}}(n=1180)\end{array}$ & $\begin{array}{l}\text { No concomitant ICS } \\
\text { use }(n=2214)\end{array}$ \\
\hline Mean age, years (SD) & $64.5(7.8)$ & $63.0(8.7)$ \\
\hline Sex, male, $n(\%)$ & $695(58.9)$ & $1358(61.3)$ \\
\hline Current smoker, $n$ (\%) & $502(42.5)$ & $1174(53.0)$ \\
\hline $\mathrm{FEV}_{1}, L(\mathrm{SD})$ & $1.27(0.47)$ & $1.45(0.54)$ \\
\hline $\begin{array}{l}\text { Post-bronchodilator } \mathrm{FEV}_{1} \text {, } \\
\% \text { predicted (SD) }\end{array}$ & $45.70(13.58)$ & $49.80(14.26)$ \\
\hline $\begin{array}{l}\text { Post-bronchodilator } \\
\text { reversibility, } n(\%)\end{array}$ & $439(37.3)$ & $872(39.5)$ \\
\hline \multicolumn{3}{|l|}{ COPD severity, $n$ (\%) } \\
\hline I (mild) & $1(0.1)$ & $4(0.2)$ \\
\hline II (moderate) & $597(50.7)$ & $1390(62.9)$ \\
\hline III (severe) & $578(49.1)$ & $804(36.4)$ \\
\hline IV (very severe) & $2(0.2)$ & $12(0.5)$ \\
\hline $\begin{array}{l}\text { Mean number of } \\
\text { exacerbations in previous } \\
12 \text { months (SD) }\end{array}$ & $0.5(0.8)$ & $0.4(0.8)$ \\
\hline \multicolumn{3}{|c|}{ Number of exacerbations in previous 12 months (\%) } \\
\hline 0 & $767(65.0)$ & $1639(74.0)$ \\
\hline 1 & $296(25.1)$ & $392(17.7)$ \\
\hline$\geq 2$ & $117(9.9)$ & $183(8.3)$ \\
\hline
\end{tabular}

COPD chronic obstructive pulmonary disease, $F E V_{1}$ forced expiratory volume in $1 \mathrm{~s}, F V C$ forced vital capacity, ICS inhaled corticosteroid, SD standard deviation

${ }^{a}$ Concomitant ICS use was defined as any ICS used at baseline (in the 15 days prior to study start), and continued throughout the treatment period

${ }^{\mathrm{b}} \mathrm{COPD}$ severity: I, FEV $1 \geq 80 \%$ predicted and $\mathrm{FEV}_{1} / \mathrm{FVC}<0.70 ; \mathrm{II}, \mathrm{FEV}_{1}$ $50-80 \%$ predicted and $\mathrm{FEV}_{1} / \mathrm{FVC}<0.70 ; \mathrm{III}, \mathrm{FEV}_{1} 30-50 \%$ predicted and $\mathrm{FEV}_{1} / \mathrm{FVC}<0.70 ; \mathrm{IV}, \mathrm{FEV}_{1}<30 \%$ predicted and $\mathrm{FEV}_{1} / \mathrm{FVC}<0.70$

baseline $(49.3 \%$ and $36.9 \%$, respectively), as was the proportion of patients with at least one exacerbation in the previous 12 months (35\% and $26 \%$, respectively) (Table 1). In the ICS subgroup, the most frequently used therapies were fluticasone $(45.3 \%$; dose range $100 \mu \mathrm{g}-1 \mathrm{mg} /$ day), budesonide (35.1\%; dose range $100 \mu \mathrm{g}-2 \mathrm{mg} /$ day) and beclomethasone (12.3\%; $100 \mu \mathrm{g}-2 \mathrm{mg} /$ day) (Table 2).

\section{Lung-function measures}

1-h post-dose $\mathrm{FEV}_{1}$. At week 24, improvements in 1-h post-dose $\mathrm{FEV}_{1}$ were observed for both doses of aclidinium/formoterol vs. placebo irrespective of ICS use $(P<0.001$ for all comparisons; Fig. 1). With aclidinium/formoterol $400 / 12 \mu \mathrm{g}$, the licensed dose, the improvements vs. placebo were $297 \mathrm{~mL}$ for ICS users and $290 \mathrm{~mL}$ for non-ICS users ( $P<0.001$ for both comparisons; Fig. 1). In ICS users, aclidinium/formoterol 400/12 $\mu \mathrm{g}$ caused an increase in 1 -h post-dose $\mathrm{FEV}_{1}$ of $108 \mathrm{~mL}$ vs. formoterol $(P<0.001)$ and $151 \mathrm{~mL}(P<0.001)$ vs. aclidinium. A similar pattern of improvement was observed with aclidinium/formoterol $400 / 12 \mu \mathrm{g}$ in nonICS users: $117 \mathrm{~mL}$ vs. formoterol and $99 \mathrm{~mL}$ vs. aclidinium (both $P<0.001)$. A direct comparison between ICS users and non-users found that there were no significant differences in $1-h$ post-dose $\mathrm{FEV}_{1}$ improvements with ICS use for any treatment group (Table 3).

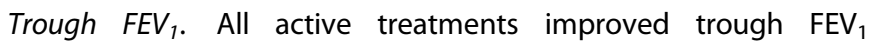
compared with placebo at week 24, irrespective of ICS use (all $P<0.05$; Fig. 2). Treatment with aclidinium/formoterol $400 / 12 \mu \mathrm{g}$
Table 2. Concomitant ICS used by the ICS group

\begin{tabular}{ll}
\hline ICS & Percentage \\
\hline Fluticasone & 45.3 \\
Budesonide & 35.1 \\
Beclomethasone & 12.3 \\
Mometasone & 4.2 \\
Ciclesonide & 3.1 \\
\hline ICS inhaled corticosteroid & \\
\hline
\end{tabular}

improved trough $\mathrm{FEV}_{1}$ vs. placebo at week 24 by $145 \mathrm{~mL}$ in ICS users and by $134 \mathrm{~mL}$ in non-ICS users $(P<0.001$ for both comparisons; Fig. 2). In ICS users, aclidinium/formoterol 400/12 $\mu \mathrm{g}$ caused an increase in trough $\mathrm{FEV}_{1}$ of $71 \mathrm{~mL}$ vs. formoterol alone $(P<0.001)$ and $54 \mathrm{~mL}(P<0.01)$ vs. aclidinium alone. A similar pattern of improvement in trough $\mathrm{FEV}_{1}$ with aclidinium/formoterol $400 / 12 \mu \mathrm{g}$ was observed in non-ICS users compared with formoterol ( $66 \mathrm{~mL} ; P<0.001)$, while the difference vs. aclidinium was $14 \mathrm{~mL}(P=0.356)$. There were no significant differences in trough $\mathrm{FEV}_{1}$ improvements when direct comparisons were made between ICS users and ICS non-users for any treatment group (Table 3).

\section{DISCUSSION}

Main findings

In this pooled analysis of two pivotal phase III trials, aclidinium/ formoterol $400 / 12 \mu \mathrm{g}$ twice daily improved bronchodilation in patients with COPD compared with placebo and monotherapies, independent of ICS use. Our findings are reassuring because it would appear that the absence of background ICS use does not blunt the therapeutic response to bronchodilator therapy.

Interpretation of findings in relation to previously published work Our results agree with those of the SHINE study, which compared the efficacy of the LABA+LAMA combination glycopyrronium and indacaterol vs. its monocomponents, tiotropium or placebo, and showed that lung function improvements were not influenced by concurrent ICS use. ${ }^{7}$ Furthermore, a recent post-hoc analysis of the OTEMTO studies also showed that the LABA+LAMA combination olodaterol and tiotropium had similar effects on lung function, symptoms and quality of life in patients with COPD using concurrent ICS, compared with non-ICS users. ${ }^{11}$ In the authors' experience, LABA+LAMA combination inhalers are more likely to be used without concurrent ICS treatment. The current analysis provides further evidence of the magnitude of lung function improvement with a LABA+LAMA combination in patients with COPD not taking ICS.

In the studies reported here, patients using an ICS at baseline were permitted to continue doing so throughout the study, resulting in a proportion of those in the aclidinium/formoterol groups receiving ICS+LAMA+LABA triple therapy. The comparison of triple vs. dual therapy was not an objective of the individual studies or this secondary pooled analysis. However, the fact that some patients received triple therapy provided us with an opportunity to explore and gain further insight into the effect of triple therapy on lung function in COPD. Previously published data demonstrated benefits of triple therapy over dual therapy with an ICS plus a single bronchodilator, and our results also demonstrated similar findings. ${ }^{12-14}$

While in many European countries high proportions (up to 86\%) of patients with COPD are treated with ICS, ${ }^{15-19}$ the burden of exacerbations would not support such widespread use. In fact, in a 
Aclidinium/formoterol 400/12 $\mu \mathrm{g}$

Aclidinium $400 \mu \mathrm{g}$

a

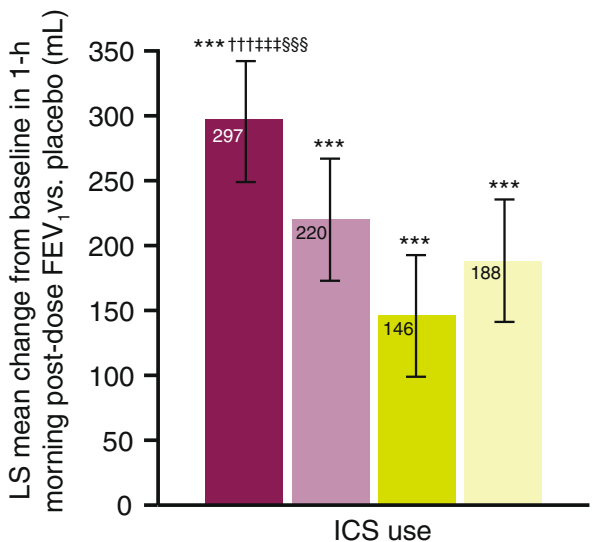

Aclidinium/formoterol 400/6 $\mu \mathrm{g}$

Formoterol $12 \mu \mathrm{g}$

b

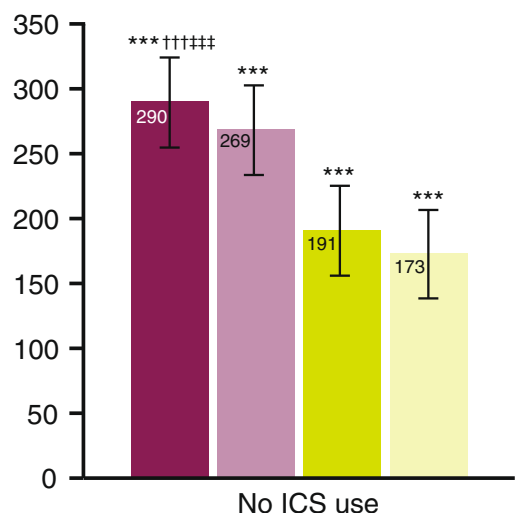

Fig. 1 LS mean change from baseline in 1-h morning post-dose FEV 1 vs. placebo at week 24 in ICS users a and non-ICS users $\mathbf{b}$ (pooled ITT population). ${ }^{* * *} P<0.001$ vs. placebo; ${ }^{\dagger+t} P<0.001$ vs. aclidinium $400 \mu \mathrm{g} ;{ }^{\ddagger \neq \neq} P<0.001 \mathrm{vs}$. formoterol $12 \mu \mathrm{g} ;{ }^{\S \S \S} P<0.001 \mathrm{vs}$. aclidinium/ formoterol $400 / 6 \mu \mathrm{g}$. Analyses based on the mixed model for repeated measures: treatment effects and treatment comparisons. Error bars represent $95 \%$ confidence intervals. Patient numbers for the placebo groups were: for patients using ICS, $n=137$, for patients not using ICS, $n=251 . F E V_{1}$ forced expiratory volume in $1 \mathrm{~s}$, ICS inhaled corticosteroid, ITT intent-to-treat, $L S$ least squares, $m L$ millilitre

Table 3. Lung function end points: ICS users vs. non-ICS users

Treatment difference ICS vs. non-ICS, $\mathrm{mL}(\mathrm{SE})$

LS mean change from baseline in 1-h post-dose $F E V_{1}$ at week 24

Placebo

19 (23)

Aclidinium/formoterol 400/12 $\mu \mathrm{g} \quad 27$ (19)

Aclidinium/formoterol 400/6 $\mu \mathrm{g} \quad-32$ (19)

Aclidinium $400 \mu \mathrm{g}$

$-33(19)$

35 (19)

LS mean change from baseline in trough $\mathrm{FEV}_{1}$ at week 24

Placebo

2 (22)

Aclidinium/formoterol 400/12 $\mu \mathrm{g}$

15 (18)

Aclidinium/formoterol $400 / 6 \mu \mathrm{g}$

$-28(18)$

Aclidinium $400 \mu \mathrm{g}$

$-32(18)$

9 (18)

$P$-value

Formoterol $12 \mu \mathrm{g}$

$F E V_{1}$ forced expiratory volume in $1 \mathrm{~s}, I C S$ inhaled corticosteroid, $L S$ least squares, $m L$ millilitre, $S E$ standard error

UK primary-care database, only $28 \%$ of patients with COPD met the Global Initiative for Chronic Obstructive Lung Disease (GOLD) criteria for high-risk, frequent exacerbators. ${ }^{20}$ The percentage of patients using an ICS at baseline in our analysis ranged from $38.7 \%$ to $40.0 \%$. However, our finding that ICS users had higher annual per-patient exacerbation rates vs. non-ICS users would be consistent with a subset population characterised by an exacerbation phenotype.

This post-hoc analysis found that improvements in lung function were similar between ICS users and non-users; however, in a previously published pooled analysis of these studies, differences in exacerbation rate and dyspnoea were observed with concomitant ICS use. ${ }^{6}$

ICS users had higher annual per-patient exacerbation rates vs. non-ICS users: 0.67 vs. 0.36 Healthcare Resource Utilisation (HCRU)-defined exacerbations; aclidinium/formoterol 400/12 $\mu \mathrm{g}$ reduced the risk of moderate/severe HCRU exacerbations vs. placebo in ICS users (rate ratio $=0.56 ; P<0.05$ ), but not in ICS nonusers (rate ratio $=0.83 ; P=0.47$ ). ${ }^{6}$ It is noteworthy that $\mathrm{FEV}_{1}$ was lower in the ICS group at baseline. These observations further underscore that ICS users in these clinical trials represent a subset of patients with different characteristics to ICS non-users; for example, they have more severe airflow obstruction and more exacerbations. Our previous analysis showed that the effect of aclidinium/formoterol $400 / 12 \mu \mathrm{g}$ on exacerbations was different in these two groups, but here we show that the effects on lung function are similar.

In our previous pooled analysis, aclidinium/formoterol $400 / 12 \mu \mathrm{g}$ caused clinically relevant improvements in dyspnoea (transitional dyspnoea index [TDI] focal score) vs. placebo regardless of concomitant ICS use. Interestingly, there were no significant improvements in TDI focal score for aclidinium/ formoterol $400 / 12 \mu \mathrm{g}$ vs. monotherapies in patients receiving ICS; however, there were improvements in ICS non-users. ${ }^{6}$ This suggests that, in terms of breathlessness, dual LAMA/LABA therapy has advantages over monotherapies in those patients who are not receiving ICS.

Strengths and limitations of this study

These are post-hoc analyses, which means that it is difficult to draw definitive conclusions. However, the large sample size means that the data on lung function presented here are likely to be a robust estimate of the effect size. Patients were not randomised by ICS use in the original studies, resulting in the observed differences in airflow obstruction and exacerbation rate between ICS and non-ICS populations at baseline. While this could be considered a limitation of this analysis, it should also be highlighted that if treatment recommendations are being applied consistently, one would expect the two populations to have different characteristics, particularly in terms of exacerbation rate. In order to circumvent these inherent differences at baseline, this analysis focused on the comparison of aclidinium/formoterol vs. placebo and monotherapies within two subgroups with and without concomitant ICS use. However, direct between-group comparisons were also performed and there were found to be no significant differences in lung function end points between ICS users and non-users. 
Aclidinium/formoterol 400/12 $\mu \mathrm{g}$ Aclidinium $400 \mu \mathrm{g}$

a

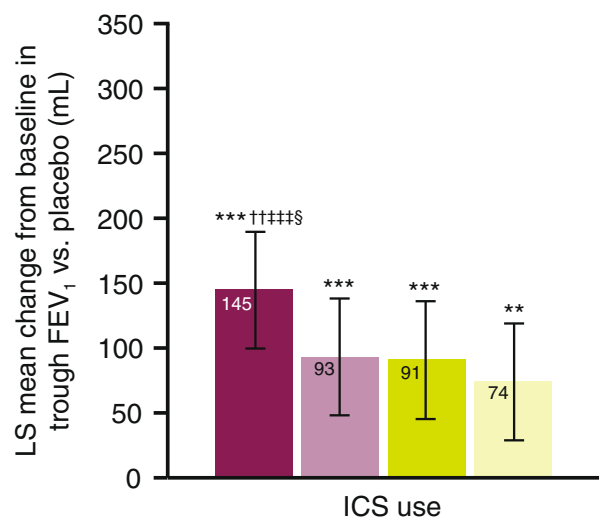

Aclidinium/formoterol 400/6 $\mu \mathrm{g}$ Formoterol $12 \mu \mathrm{g}$

b

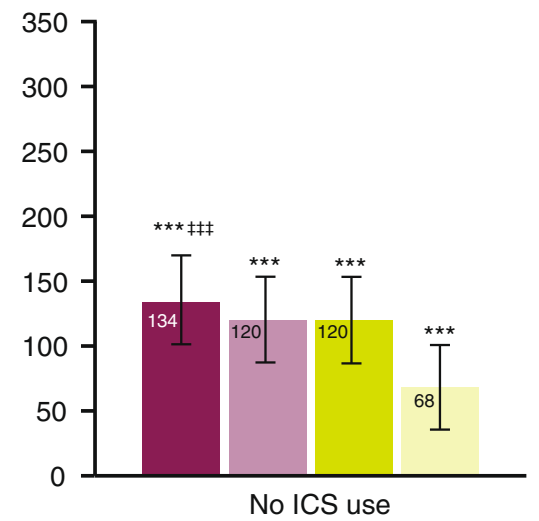

Fig. 2 LS mean change from baseline in trough $\mathrm{FEV}_{1}$ vs. placebo at week 24 in ICS users a and non-ICS users $\mathbf{b}$ (pooled ITT population) ${ }^{* *} P<0.01$ vs. placebo; ${ }^{* *} P<0.001$ vs. placebo; ${ }^{++} P<0.01$ vs. aclidinium $400 \mu \mathrm{g} ;{ }^{* \neq \ddagger} P<0.001$ vs. formoterol $12 \mu \mathrm{g} ;{ }^{\S} P<0.05 \mathrm{vs}$. aclidinium/ formoterol $400 / 6 \mu \mathrm{g}$. Analyses based on the mixed model for repeated measures: treatment effects and treatment comparisons. Error bars represent $95 \%$ confidence intervals. Patient numbers for the placebo groups were: for patients using ICS, $n=137$, for patients not using ICS, $n=254$. $F E V_{1}$ forced expiratory volume in $1 \mathrm{~s}$, ICS inhaled corticosteroid, ITT intent-to-treat, $L S$ least squares, $m L$ millilitre

Implications for future research, policy and practice

The analysis reported here demonstrates that aclidinium/formoterol $400 / 12 \mu \mathrm{g}$ improves lung function compared with placebo and monotherapies regardless of ICS use. It is not clear whether this relates to recent research suggesting that lung function is a relatively poor predictor of exacerbations, ${ }^{21}$ but it does suggest that while there is a common benefit of this dual combination bronchodilator on lung function in both groups of patients, this lung-function effect is associated with different clinical benefits depending on whether or not a concomitant ICS is used. It is useful to note that prior to the 2017 update, the GOLD strategy recommended treatment based on risk rather than exacerbation phenotype, allowing most of the patients in GOLD groups $C$ and $D$ to qualify for these categories based on lung function alone, rather than frequent exacerbations, or both. ${ }^{22}$ A relevant clinical message that emerges from our findings is the importance of identifying patients with an exacerbation phenotype who are most likely to benefit from ICS in combination with dual bronchodilator therapy.

\section{CONCLUSION}

The analysis reported here demonstrates that aclidinium/formoterol $400 / 12 \mu \mathrm{g}$ improves lung function compared with placebo and monotherapies regardless of ICS use. However, this lungfunction effect is associated with different clinical benefits depending on whether or not a concomitant ICS is used, highlighting the importance of identifying patients who are most likely to benefit from ICS in combination with dual bronchodilator therapy, such as aclidinium/formoterol.

\section{METHODS}

This was a subgroup analysis of pooled data from ACLIFORM (NCT01462942) and AUGMENT (NCT01437397) according to concomitant ICS use (user vs. non-user) for aclidinium/formoterol 400/12 $\mu \mathrm{g}$ (the approved dose). Methods, overall efficacy, tolerability and safety results have been published previously. ${ }^{4} 5$ In brief, the studies included adults aged $\geq 40$ years, current or former smokers ( $\geq 10$ pack-years) with moderate to severe stable COPD, a post-bronchodilator $\mathrm{FEV}_{1} /$ forced vital capacity ratio of $<70 \%$ and a post-bronchodilator $\mathrm{FEV}_{1} \geq 30 \%$ and $<80 \%$ predicted. Patients with a history or current diagnosis of asthma, a respiratory tract infection or COPD exacerbation within 6 weeks $(<3$ months if hospitalised) prior to screening, or clinically significant respiratory or cardiovascular conditions other than COPD were excluded. Patients were randomised (by centralised interactive voice response system) to receive twice-daily aclidinium/formoterol $400 / 12 \mu \mathrm{g}$, aclidinium/formoterol $400 / 6 \mu \mathrm{g}$, aclidinium $400 \mu \mathrm{g}$, formoterol $12 \mu \mathrm{g}$ or placebo (all via the drypowder inhaler Genuair ${ }^{\mathrm{TM}} /$ Pressair $\left.^{\circ}{ }^{\circ}\right)$. Concomitant use of ICS, oral or parenteral corticosteroids $(\leq 10 \mathrm{mg} /$ day or $20 \mathrm{mg}$ every other day of prednisone) was allowed if treatment was stable $\geq 4$ weeks prior to screening. The use of albuterol/salbutamol was permitted as rescue medication.

Here, we report results for the co-primary efficacy end points, change from baseline in morning pre-dose (trough) and morning 1-h post-dose $\mathrm{FEV}_{1}$ at week 24. Lung function was assessed by standardised spirometric techniques at each study visit (weeks 1, 4, 12, 18 and 24). Trough FEV 1 was derived as the average of the two best FEV ${ }_{1}$ values obtained before the morning dose, and morning 1 - $\mathrm{h}$ post-dose $\mathrm{FEV}_{1}$ was the maximum $\mathrm{FEV}_{1}$ reading from $1 \mathrm{~h}$ after the morning dose.

The studies were approved by an independent ethics committee at each site and were conducted in accordance with the Declaration of Helsinki, the International Conference on Harmonisation and Good Clinical Practice. All patients provided written informed consent.

\section{Statistical analyses}

Efficacy analyses were performed in the intent-to-treat population (all randomised patients who took $\geq 1$ dose of study medication and had a baseline and $\geq 1$ post-baseline $\mathrm{FEV}_{1}$ assessment). Analysis of the co-primary end points was performed via a mixed model for repeated measures, stratified for concomitant ICS use (prespecified for morning 1-h post-dose FEV $_{1}$ and trough FEV $_{1}$ ) with treatment group, sex, smoking status, visit, subgroup, and treatment-group-by-subgroup, treatment-group-by-visit and treatment-group-by-visit-by-subgroup interactions as fixed-effect factors, corresponding baseline values and age as covariates, and preand post-bronchodilator $\mathrm{FEV}_{1}$ as a covariate for $\mathrm{FEV}_{1}$ end points. For this pooled evaluation, data analysis was carried out post-hoc and, therefore, no adjustment was made for multiplicity.

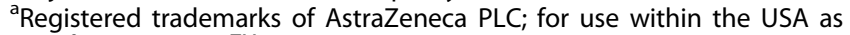
Pressair and Genuair ${ }^{\mathrm{TM}}$ within all other licensed territories.

\section{ACKNOWLEDGEMENTS}

The authors would like to thank all of the patients and their families, the team of investigators, research nurses and operations staff involved in the ACLIFORM and AUGMENT studies. Medical writing support was provided by Tracey Lonergan and Jennifer Higginson of Complete Medical Communications under the direction of the authors, funded by AstraZeneca. The sponsor was involved in the design of the study, analysis of the data and reviewed the manuscript for intellectual property and 
medical accuracy. These studies were funded by Almirall S.A. and Forest Laboratories, LLC., an Allergan affiliate.

\section{AUTHOR CONTRIBUTIONS}

All authors were involved in drafting, reviewing and revising the manuscript for intellectual content and approved the final version of the manuscript for submission.

\section{COMPETING INTERESTS}

A.D. has received research, consulting and lecturing fees from GlaxoSmithKline, Sepracor, Schering-Plough, Altana, Methapharm, AstraZeneca, ONO Pharmaceutical Co., Merck Canada, Forest Laboratories, Novartis Canada/USA, Boehringer Ingelheim (Canada) Ltd, Pfizer Canada, SkyePharma, KOS Pharmaceuticals and Almirall. D.S. has received travel reimbursement, research, consulting and lecturing fees from Almirall, AstraZeneca, Boehringer Ingelheim, Chiesi, Genentech, GlaxoSmithKline, Glenmark, Merck, NAPP, Novartis, Pfizer, Respivert, SkyePharma, Takeda, Teva, Theravance and Verona. E.G.G. is an employee of AstraZeneca and a former employee of Almirall S.A., Barcelona, Spain.

\section{REFERENCES}

1. European Medicines Agency. Duaklir Genuair ${ }^{\mathrm{TM}}$ (aclidinium bromide / formoterol fumarate dihydrate), http://www.ema.europa.eu/ema/index.jsp? curl=pages/medicines/human/medicines/003745/human_med_001811. jsp\&mid=WC0b01ac058001d124, Accessed 28 November 2016.

2. Health Canada. Health Canada Regulatory Decision Summary: DUAKLIR GENUAIR, http://www.hc-sc.gc.ca/dhp-mps/prodpharma/rds-sdr/drug-med/ rds_sdr_duaklir_genuair_172711-eng.php, Accessed 28 November 2016.

3. Australian Register of Therapeutic Goods. Public ARTG Summary BRIMICA GENUAIR 340/12 aclidinium bromide and eformoterol fumarate dihydrate powder for inhalation dry powder inhaler, https://www.ebs.tga.gov.au/servlet/xmlmillr6? $\mathrm{dbid}=\mathrm{ebs} /$ PublicHTML/pdfStore.nsf\&docid=7D48BD935C36BFE5CA257E3800423 B12\&agid=(PrintDetailsPublic)\&actionid=1, Accessed 28 November 2016.

4. D'Urzo, A. D. et al. Efficacy and safety of fixed-dose combinations of aclidinium bromide/formoterol fumarate: the 24-week, randomized, placebo-controlled AUGMENT COPD study. Respir. Res. 15, 123-141 (2014).

5. Singh, D. et al. Efficacy and safety of aclidinium bromide/formoterol fumarate fixed-dose combinations compared with individual components and placebo in patients with COPD (ACLIFORM-COPD): a multicentre, randomised study. BMC Pulm. Med. 14, 178-189 (2014).

6. Bateman, E. D. et al. Aclidinium bromide and formoterol fumarate as a fixed-dose combination in COPD: pooled analysis of symptoms and exacerbations from two six-month, multicentre, randomised studies (ACLIFORM and AUGMENT). Respir. Res. 16, 92 (2015).

7. Bateman, E. D. et al. Dual bronchodilation with QVA149 versus single bronchodilator therapy: the SHINE study. Eur. Respir. J. 42, 1484-1494 (2013).

8. Buhl, R. et al. Tiotropium and olodaterol fixed-dose combination versus monocomponents in COPD (GOLD 2-4). Eur. Respir. J. 45, 969-979 (2015).
9. Donohue, J. F. et al. Efficacy and safety of once-daily umeclidinium/vilanterol $62.5 / 25 \mathrm{mcg}$ in COPD. Respir. Med. 107, 1538-1546 (2013).

10. Global Initiative for Chronic Obstructive Lung Disease. Global strategy for the diagnosis, management, and prevention of chronic obstructive pulmonary disease, http://goldcopd.org/gold-reports/, Accessed 28 November 2016.

11. Singh, D. et al. Effects of tiotropium + olodaterol versus tiotropium or placebo by COPD disease severity and previous treatment history in the OTEMTO ${ }^{\circledast}$ studies. Respir. Res. 17, 73 (2016).

12. Frith, P. A. et al. Glycopyrronium once-daily significantly improves lung function and health status when combined with salmeterol/fluticasone in patients with COPD: the GLISTEN study, a randomised controlled trial. Thorax 70, 519-527 (2015).

13. Singh, D., Brooks, J., Hagan, G., Cahn, A. \& O'Connor, B. J. Superiority of "triple" therapy with salmeterol/fluticasone propionate and tiotropium bromide versus individual components in moderate to severe COPD. Thorax 63, 592-598 (2008).

14. Singh, D. et al. Single inhaler triple therapy versus inhaled corticosteroid plus long-acting beta2-agonist therapy for chronic obstructive pulmonary disease (TRILOGY): a double-blind, parallel group, randomised controlled trial. Lancet $\mathbf{3 8 8}$, 963-973 (2016).

15. Cazzola, M. et al. Change in asthma and COPD prescribing by Italian general practitioners between 2006 and 2008. Prim. Care Respir. J. 20, 291-298 (2011).

16. Drivenes, E., Ostrem, A. \& Melbye, H. Predictors of ICS/LABA prescribing in COPD patients: a study from general practice. BMC Fam. Pract. 15, 42 (2014).

17. Izquierdo, J. L. et al. Misdiagnosis of patients receiving inhaled therapies in primary care. Int. J. Chron. Obstruct. Pulmon. Dis. 5, 241-249 (2010).

18. Mehuys, E. et al. COPD management in primary care: an observational, community pharmacy-based study. Ann. Pharmacother. 44, 257-266 (2010).

19. Price, D. et al. Management of COPD in the UK primary-care setting: an analysis of real-life prescribing patterns. Int. J. Chron. Obstruct. Pulmon. Dis. 9, 889-904 (2014).

20. McGarvey, L. et al. Characterisation of the frequent exacerbator phenotype in COPD patients in a large UK primary care population. Respir. Med. 109, 228-237 (2015).

21. Kerkhof, M., Freeman, D., Jones, R., Chisholm, A. \& Price, D. B. Predicting frequent COPD exacerbations using primary care data. Int. J. Chron. Obstruct. Pulmon. Dis. 10, 2439-2450 (2015).

22. Agusti, A. et al. FAQs about the GOLD 2011 assessment proposal of COPD: a comparative analysis of four different cohorts. Eur. Respir. J. 42, 1391-1401 (2013).

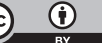

This work is licensed under a Creative Commons Attribution 4.0 International License. The images or other third party material in this article are included in the article's Creative Commons license, unless indicated otherwise in the credit line; if the material is not included under the Creative Commons license, users will need to obtain permission from the license holder to reproduce the material. To view a copy of this license, visit http://creativecommons.org/licenses/by/ 4.0/

(c) The Author(s) 2017 